\title{
Modeling $\mathrm{O}_{2}$ Transport as an Integrated System Limiting $\dot{\mathrm{VO}} \mathrm{O}_{2} \mathrm{MAX}$
}

Peter D. Wagner, M.D.

Department of Medicine, University of California, San Diego, La Jolla, CA, USA

\begin{abstract}
Maximal endurance exercise capacity is determined by a variety of factors, including maximal ability to transport $\mathrm{O}_{2}$ to the muscle mitochondria and to use this $\mathrm{O}_{2}$ for ATP generation $\left(\mathrm{VO}_{2} \mathrm{MAX}\right)$. This analysis combines the individually well-known $\mathrm{O}_{2}$ mass conservation equations for the four critical steps in the $\mathrm{O}_{2}$ transport pathway (ventilation, alveolar/capillary diffusion, circulation and muscle diffusion) into an analytical, closed form, model showing how $\mathrm{VO}_{2} \mathrm{MAX}$ depends on all four steps. It further shows how changes in any one step affect the function of the others. This analytical approach however requires approximating the $\mathrm{O}_{2} \mathrm{Hb}$ dissociation curve as linear. Removing this condition to allow for the real $\mathrm{O}_{2} \mathrm{Hb}$ curve requires numerical analysis best explained graphically. Incorporating maximal mitochondrial metabolic capacity to use $\mathrm{O}_{2}$ allows prediction of when $\mathrm{VO}_{2} \mathrm{MAX}$ is limited by transport or by metabolic capacity. This simple approach recapitulates in vivo behavior and clarifies the determinants of maximal exercise.
\end{abstract}

\section{Keywords}

maximal $\mathrm{O}_{2}$ consumption; maximal exercise capacity; oxygen transport; oxygen utilization

Endurance exercise depends on delivering $\mathrm{O}_{2}$ from the air to the contracting muscle mitochondria. This $\mathrm{O}_{2}$ pathway is very well understood in terms of its individual steps [1] (Figure 1), but there remains considerable misunderstanding about how the steps relate to one another and combine to determine maximal $\mathrm{O}_{2}$ throughput. Modeling $\mathrm{O}_{2}$ transport as an integrated system offers the opportunity to clarify how the system works and which steps are important to overall function. To do this requires appreciation of three principal issues: First, the four main steps shown in Figure 1 (ventilation, alveolar-capillary diffusion, circulation, and muscle diffusion) form an in series set of steps for $\mathrm{O}_{2}$ as molecules are passed from the air to the lungs to the blood and finally to the mitochondria. Second, $\mathrm{O}_{2}$ throughput at each step must conserve $\mathrm{O}_{2}$ mass. Finally, for present purposes, the system should be considered in a steady state, such that the transients at the onset and cessation of exercise are removed from consideration.

Under these constraints, well known transport equations exist for each step. These were described some 60 years ago [2-5]. The equations describing transport by convective processes (ventilation and circulation) simply conserve mass; those describing transport by

Peter D. Wagner, M.D., Distinguished Professor of Medicine and Bioengineering, Division of Physiology, Department of Medicine, University of California, San Diego, 9500 Gilman Drive, DEPT 0623A, La Jolla, CA, 92093-0623A USA, (858) 534-4190 (phone), (858) 534-4812 (fax), pdwagner@ucsd.edu.

Publisher's Disclaimer: This is a PDF file of an unedited manuscript that has been accepted for publication. As a service to our customers we are providing this early version of the manuscript. The manuscript will undergo copyediting, typesetting, and review of the resulting proof before it is published in its final citable form. Please note that during the production process errors may be discovered which could affect the content, and all legal disclaimers that apply to the journal pertain. 
diffusive processes start as first order linear differential equations that must be integrated along the relevant capillary path to yield overall mass conservation and $\mathrm{O}_{2}$ throughput from start to end of the capillary.

The purpose of this analysis is to bring these separate equations together as a system, and from this to examine how the system functions. To do this, either of two approaches could be used. One is to approximate the $\mathrm{O}_{2} \mathrm{Hb}$ dissociation curve by a straight line (the slope being modeled by a single constant) rather than using the complex non-linear function that it really is [5-6]. The other is to use the actual $\mathrm{O}_{2} \mathrm{Hb}$ dissociation curve [7]. The former allows algebraic analysis with closed form solutions that give a clear overview of the principles of system function at the cost of strict numerical accuracy. The latter provides accurate simulation for $\mathrm{O}_{2}$ transport, but the complex nature of the dissociation curve precludes analytical solutions. Thus, numerical analysis must be applied, and this means that each such computation yields a particular solution correct and applicable only for the values of the chosen variables. These two approaches are nicely complementary and both will be addressed in what follows.

\section{$\mathrm{O}_{2}$ transport modeled using linear approximation to the $\mathrm{O}_{2} \mathrm{Hb}$ dissociation curve}

Figure 2 presents at the top the mass balance equations for each of the four processes [4-5]. Those describing diffusion (at both the lungs and muscles) have already been integrated to provide the overall solution. These equations are each far from novel as mentioned above. What should be realized is that these four equations contain precisely four unknowns as set out in Figure 2. Therefore, this equation set can be solved algebraically, and the solutions for the four unknowns are also laid out in Figure 2.

In Figure 3, the top section shows these solutions graphically as just one of the input variables, maximal cardiac output, is systematically altered across the spectrum from 0 to 50 $1 /$ minute using data for all variables corresponding to maximal exercise for normal fit young adults. Oxygen uptake varies as would be expected, cardiac output being just one component of an in series transport system. It governs $\mathrm{VO}_{2}$ when low $(<10 \mathrm{~L} / \mathrm{min})$, but has little effect when higher. This characteristic non-linear behavior of $\mathrm{VO}_{2}$ is explained by the basic governing equations (top of Figure 2). The higher the cardiac output, the greater is the convective flow of $\mathrm{O}_{2}$ within the circulatory system (blood flow equation). However, the two equations describing diffusion each have an exponential term with blood flow, $Q$, in the denominator of the exponent. Thus, as $\mathbf{Q}$ increases, there is less and less complete diffusive equilibration in both the lungs and muscles, offsetting the enhancement by the circulatory component mentioned above. As $\mathrm{Q}$ increases, the fall in arterial $\mathrm{PO}_{2}$ and rise in venous $\mathrm{PO}_{2}$ shown in figure 3 reflect this interference to diffusive transport and limit the gain in $\mathrm{VO}_{2} \mathrm{MAX}$ with increasing $\mathrm{Q}$.

This pattern of behavior is seen when any of the independent transport variables (Figure 2) is altered, as shown in the bottom panel of Figure 3. Except for the linear relationship between $\mathrm{VO}_{2} \mathrm{MAX}$ and $\mathrm{PIO}_{2}$ (which is an artifact of assuming the $\mathrm{O}_{2} \mathrm{Hb}$ dissociation curve is linear as $\mathrm{PIO}_{2}$ increases), the effects of changing any of the independent variables are similar as Figure 3 shows. The major point of this analysis is that in an in series system such as that for $\mathrm{O}_{2}$ transport, every component has the potential to affect $\mathrm{VO}_{2} \mathrm{MAX}$. The standard question of "what limits $\mathrm{VO}_{2} \mathrm{MAX}$ : is it the heart, the lungs or the muscle?" needs to be replaced by the question "how important are the various independent variables to $\mathrm{VO}_{2} \mathrm{MAX}$ ?" There is no one determinant of maximal $\mathrm{VO}_{2}$. 


\section{$\mathrm{O}_{2}$ transport modeled using the actual $\mathrm{O}_{2} \mathrm{Hb}$ dissociation curve}

Figures 2 and 3 demonstrate the power of analytical approaches to the $\mathrm{O}_{2}$ transport system, but also reveal the approximations resulting from assuming a linear $\mathrm{O}_{2} \mathrm{Hb}$ dissociation curve. Numerical analysis to solve the equation system of Figure 2 reconfigured to use the actual dissociation curve is feasible. Because each simulation produces a particular result [7], a more efficient way to present system behavior is to use a graphical approach [8]. Figure 4 shows the conceptual basis for this approach. Panel A describes the coexistent transport processes of blood flow to, and diffusion within, muscle. Panel B focuses on the convective, circulatory transport component using the well-known Fick principle of mass conservation (as also used in Figure 2). Panel C focuses on the diffusive transport of $\mathrm{O}_{2}$ from muscle microvascular red cells to muscle mitochondria, using the laws of diffusion. The equations now reflect the actual dissociation curve. For the diffusive component, $\mathrm{PcapO}_{2}$ represents mean capillary $\mathrm{PO}_{2}$ between the artery and vein, which in effect serves to integrate $\mathrm{O}_{2}$ diffusion along the capillary length. In panel $\mathrm{C}, \mathrm{O}_{2}$ flux is given by the product of the muscle diffusing capacity, $\mathrm{D}$, and the difference between the mean capillary $\mathrm{PO}_{2}$ $\left(\mathrm{PcapO}_{2}\right)$ and the mitochondrial $\mathrm{PO}_{2}\left(\mathrm{PmitoO}_{2}\right)$.

Two important approximations are now made to simplify the presentation: First, mitochondrial $\mathrm{PO}_{2}$ is taken to be zero. It must be less than $3-4 \mathrm{~mm} \mathrm{Hg}$, which is the measured value of the $\mathrm{PO}_{2}$ associated with myoglobin in the cytoplasm during heavy exercise [9]. Mean capillary $\mathrm{PO}_{2}$ on the other hand is about $40-50 \mathrm{~mm} \mathrm{Hg}$, calculated by numerical analysis between measured values of arterial and muscle venous $\mathrm{PO}_{2}$ [10]. The second approximation is to replace $\mathrm{PcapO}_{2}$ by a constant, $\mathrm{k}$, multiplying $\mathrm{PvO}_{2}$ (muscle venous $\mathrm{PO}_{2}$ ). This too has been shown to be reasonable [10]. The two transport equations of Figure 4 may now be written:

$$
\begin{aligned}
& \qquad \dot{\mathrm{V}} \mathrm{O}_{2}=\dot{\mathrm{Q}} \times\left[\mathrm{CaO}_{2}-\mathrm{CvO}_{2}\right] \\
& \dot{\mathrm{V}} \mathrm{O}_{2}=\mathrm{D} \times\left[\mathrm{PCAPO}_{2}-\mathrm{PMITOO}_{2}\right]=\mathrm{D} \times \mathrm{k} \times \mathrm{PvO}_{2} \\
& \text { These two equations are plotted in Panel A of Figure 5, with } \mathrm{VO}_{2} \text { on the ordinate and } \mathrm{PvO}_{2} \\
& \text { on the abscissa, assuming PmitoO } \\
& \text { equation } 1 \text { above, the equation describing convective blood flow. The open square marks } \\
& \text { what would be seen if all } \mathrm{O}_{2} \text { was extracted from the flowing blood; the closed square if no } \\
& \mathrm{O}_{2} \text { at all were extracted from the flowing blood. Neither extreme is ever seen in practice. }
\end{aligned}
$$

It can be seen that the only point in the figure where both equations yield the same $\mathrm{VO}_{2}$ and $\mathrm{PvO}_{2}$ - requirements of mass conservation - is that point marked by the solid circle. The values for the independent variables $(\mathrm{Q}, \mathrm{D},[\mathrm{Hb}])$ are those at maximal exercise, with arterial $\mathrm{O}_{2}$ concentration additionally depending on lung diffusing capacity and ventilation at maximal exercise. Thus, the solid circle identifies $\mathrm{VO}_{2} \mathrm{MAX}$, and shows it to be a function of all of the independent variables listed in Figure 2.

Panels B, C and D indicate how individual changes in key independent variables (inspired $\mathrm{PO}_{2}$, ventilation and lung diffusing capacity and hence arterial $\mathrm{PO}_{2}(\mathrm{~B})$; muscle diffusing capacity (C); and blood flow (D)) would affect $\mathrm{VO}_{2} \mathrm{MAX}$ (and $\mathrm{PvO}_{2}$ ). In particular, changing inspired $\mathrm{PO}_{2}$ is predicted to produce a linear and proportional relationship between $\mathrm{VO}_{2} \mathrm{MAX}$ and $\mathrm{PvO}_{2}$, and this has been found repeatedly [10-11]. Panels $\mathrm{C}$ and $\mathrm{D}$ contrast the effects of reduced diffusing capacity versus impaired blood flow: the former reduces 
$\dot{\mathrm{VO}}_{2} \mathrm{MAX}$ but increases $\mathrm{PvO}_{2}$, while the latter reduces $\mathrm{PvO}_{2}$ as $\mathrm{VO}_{2} \mathrm{MAX}$ is lowered. Thus, different causes of any observed reduction in $\mathrm{VO}_{2} \mathrm{MAX}$ can be analyzed on Figure 5 if the relevant data are available, allowing the separate contributions of any changes in each transport variable to be determined.

\section{Mitochondrial metabolic capacity: interaction with $\mathrm{O}_{2}$ transport in determining $\mathrm{V}_{2} \mathrm{MAX}$}

To this point, it has been implicitly assumed that $\mathrm{O}_{2}$ transport governs maximal $\mathrm{VO}_{2}$. In other words, that the capacity to use $\mathrm{O}_{2}$ for ATP generation exceeds the capacity of the transport system to deliver $\mathrm{O}_{2}$ to the mitochondria. However, it is also possible that the $\mathrm{O}_{2}$ transport system can supply enough $\mathrm{O}_{2}$ to meet the maximal demands of the mitochondria for $\mathrm{O}_{2}$. In this case, it would be maximal mitochondrial oxidative capacity (MMOC) and not transport that limited maximal $\mathrm{O}_{2}$ consumption. Figure 6 explores this possibility, integrating it with $\mathrm{O}_{2}$ transport. In panel $\mathrm{A}$ are shown data from Wilson et al showing how isolated mitochondrial $\mathrm{VO}_{2}$ depends on ambient $\mathrm{PO}_{2}$. Above a $\mathrm{PO}_{2}$ of about $2 \mathrm{~mm} \mathrm{Hg}$, mitochondrial $\mathrm{VO}_{2}$ is independent of $\mathrm{PO}_{2}$, and this plateau $\mathrm{VO}_{2}$ value constitutes MMOC. This can be added to the diagrams of Figure 5. In panels $\mathrm{B}$ and $\mathrm{C}$ are shown hypothetical effects of a high (B) and low (C) MMOC. In B, MMOC exceeds $\mathrm{O}_{2}$ transport capacity even at the highest of the three levels of oxygenation shown. In this example, $\mathrm{VO}_{2} \mathrm{MAX}$ falls as $\mathrm{FIO}_{2}$ is reduced, exactly as in Figure 5B. However, in a subject with very low MMOC (Figure 6C), but identical $\mathrm{O}_{2}$ transport capacity as the subject in Figure 6B, a different outcome will be seen. With changes in $\mathrm{FIO}_{2}, \mathrm{VO}_{2} \mathrm{MAX}$ will vary in proportion to $\mathrm{PvO}_{2}$ only when $\mathrm{FIO}_{2}$ is low enough that $\mathrm{VO}_{2}$ is less than MMOC. At higher $\mathrm{FIO}_{2}, \mathrm{VO}_{2} \mathrm{MAX}$ fails to increase linearly, and plateaus at the MMOC value. Figure 6D shows that indeed these two patterns can be seen in healthy subjects [11-12]. By and large, trained athletes emulate Figure $6 \mathrm{~B}$ while sedentary untrained subjects follow Figure $6 \mathrm{C}$. Thus, this analysis suggests that in fit subjects, $\mathrm{O}_{2}$ transport limits $\mathrm{VO}_{2} \mathrm{MAX}$, while in unfit subjects, mitochondrial oxidative enzyme capacity sets the limit to $\mathrm{VO}_{2} \mathrm{MAX}$, until imposed hypoxia becomes severe.

In summary, the $\mathrm{O}_{2}$ transport and utilization system is an in series system in which every component is important to overall system throughput of $\mathrm{O}_{2}$. Bringing together the wellestablished $\mathrm{O}_{2}$ transport equations for the four main $\mathrm{O}_{2}$ transport processes (ventilation, alveolar-capillary diffusion, circulation and muscle diffusion), analytical solutions for transport can be found if the $\mathrm{O}_{2} \mathrm{Hb}$ dissociation curve is approximated by a straight line. This shows how every transport component has the power to affect $\mathrm{VO}_{2} \mathrm{MAX}$ - there is no single limiting factor. To account for the non-linearity of the dissociation curve, numerical analysis is required, but a simple diagram plotting $\mathrm{VO}_{2}$ against muscle venous $\mathrm{PO}_{2}$ can achieve this and yields great insight into the integrative nature of the $\mathrm{O}_{2}$ transport and utilization process.

\section{References}

1. Weibel, ER. Structure and Function in the Mammalian Respiratory System. Cambridge, MA: Harvard University Press; 1984. The Pathway for Oxygen.

2. Rahn, H.; Fenn, WO. A Graphical Analysis of the Respiratory Gas Exchange. Washington, D.C: American Physiological Society; 1955.

3. Riley RL, Cournand A. "Ideal" alveolar air and the analysis of ventilation/perfusion relationships in the lung. J Appl Physiol 1949;1:825-47. [PubMed: 18145478]

4. Kety SS. The theory and applications of the exchange of inert gas at the lungs and tissues. Pharmacol Rev 1951;3:1-41. [PubMed: 14833874] 
5. Piiper J, Scheid P. Model for capillary-alveolar equilibration with special reference to $\mathrm{O}_{2}$ uptake in hypoxia. Respir Physiol 1981;46:193-208. [PubMed: 6798659]

6. Wagner PD. Algebraic analysis of the determinants of $\mathrm{VO}_{2} \mathrm{MAX}$. Respir Physiol 1993;93:221-237. [PubMed: 8210760]

7. Wagner PD. A theoretical analysis of factors determining $\mathrm{VO}_{2} \mathrm{MAX}$ at sea level and altitude. Resp Physiol 1996;106:329-343.

8. Wagner PD. Determinants of maximal oxygen transport and utilization. Annu Rev Physiol 1996;58:21-50. [PubMed: 8815793]

9. Richardson RS, Noyszewski EA, Kendrick KF, Leigh JS, Wagner PD. Myoglobin $\mathrm{O}_{2}$ desaturation during exercise: evidence of limited $\mathrm{O}_{2}$ transport. J Clin Invest 1995;96:1916-1926. [PubMed: 7560083]

10. Roca J, Ramis LI, Rodriguez-Roisin R, Ballester E, Montserrat JM, Wagner PD. Serial relationships between ventilation/perfusion inequality and spirometry in acute severe asthma requiring hospitalization. Am Rev Respir Dis 1988;137:1055-1061. [PubMed: 3195803]

11. Richardson RS, Grassi B, Gavin TP, Haseler LJ, Tagore K, Roca J, Wagner PD. Evidence of $\mathrm{O}_{2}$ supply-dependent $\mathrm{VO}_{2} \mathrm{MAX}$ in the exercise-trained human quadriceps. J Appl Physiol 1999;86:1048-1053. [PubMed: 10066722]

12. Cardús J, Marrades RM, Roca J, Barberá JA, Diaz O, Masclans JR, Rodriguez-Roisin R, Wagner PD. Effects of $\mathrm{FIO}_{2}$ on leg $\mathrm{VO}_{2}$ during cycle ergometry in sedentary subjects. Med Sci Sports Exerc 1998;30:697-703. [PubMed: 9588611]

13. Wilson DF, Erecinska M, Drown C, Silver IA. Effect of oxygen tension on cellular energetics. Am J Physiol 1977;2:C135-C140. [PubMed: 200145] 


\section{The $\mathrm{O}_{2}$ transport system}

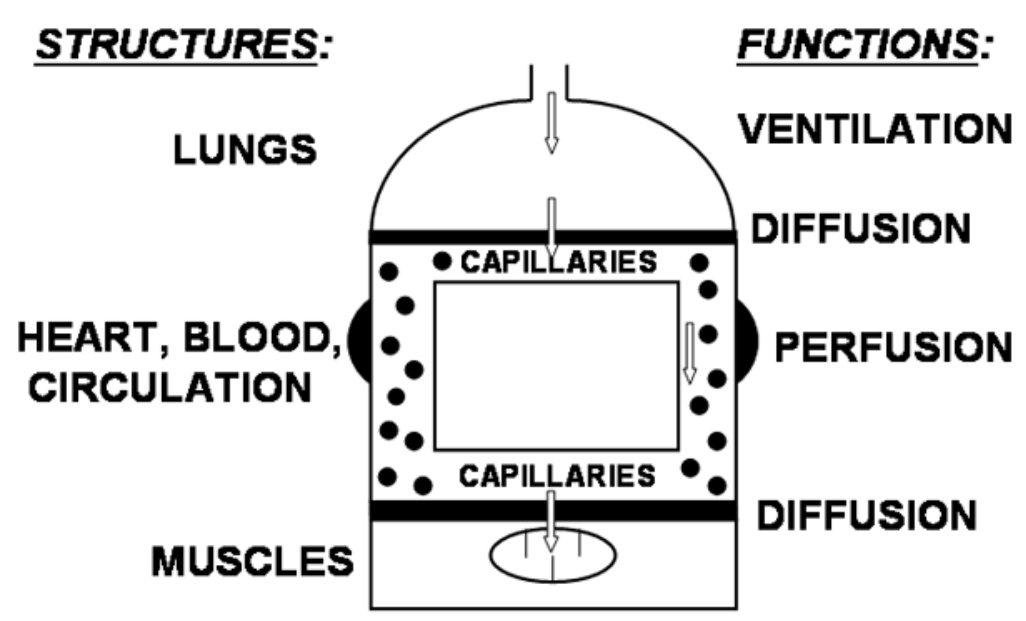

Figure 1.

Diagram of the $\mathrm{O}_{2}$ transport system, consisting of four major organs/tissues (lungs, cardiovascular system, blood and muscle) supporting the four principal transport functions (ventilation, alveolar-capillary diffusion, circulatory perfusion and muscle diffusion). 


\section{FOUR EQUATIONS, WITH FOUR UNKNOWNS}

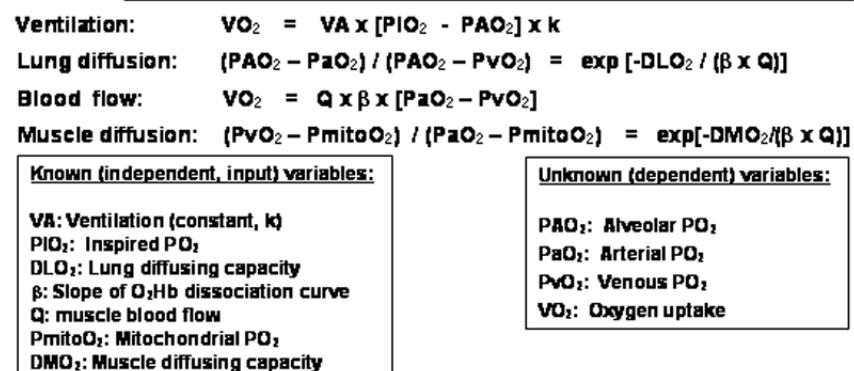

\section{AND THEIR SOLUTIONS}

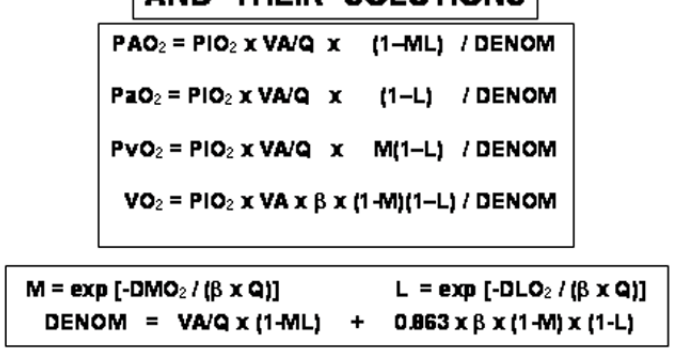

Figure 2.

By approximating the $\mathrm{O}_{2} \mathrm{Hb}$ dissociation curve as a straight line, the four $\mathrm{O}_{2}$ transport functions are each described by explicit equations that can be solved simultaneously to yield analytical solutions for the four indicated dependent variables in terms of given values of the seven independent variables listed. These solutions are given in the lower section of the figure. 
CONSEQUENCES OF CHANGES IN TRANSPORT VARIABLES
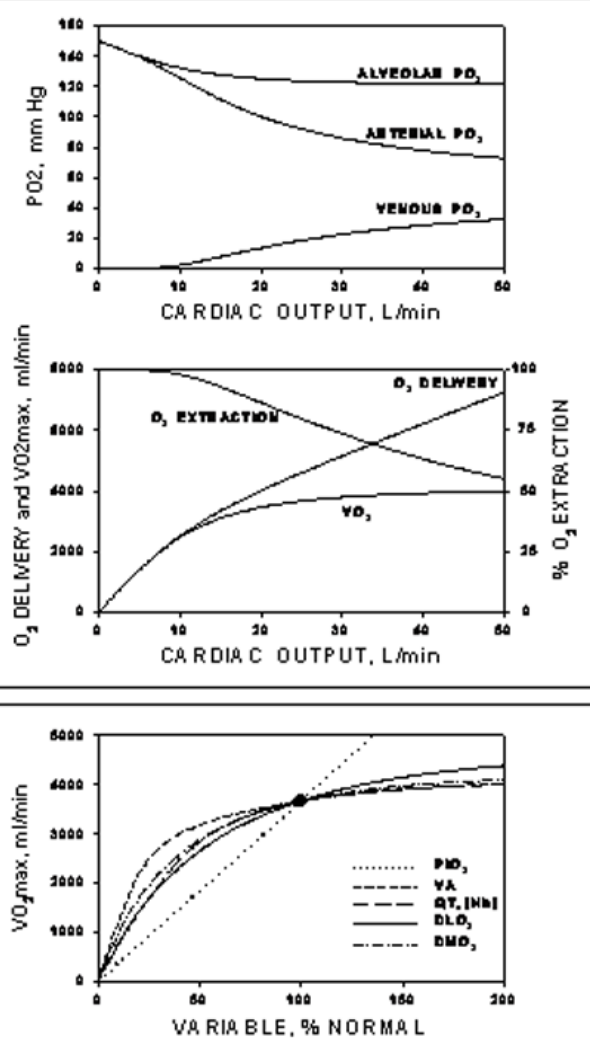

Figure 3.

Upper box: Graphical expression of the solutions listed in Figure 2 for the case of changing cardiac output. Lower box: Summary solutions for the effects on $\mathrm{VO}_{2} \mathrm{MAX}$ of varying each independent variable one at a time. Except for the effects of $\mathrm{PIO}_{2}$ (which reflect the linear approximation to the $\mathrm{O}_{2} \mathrm{Hb}$ dissociation curve), the effects of all other variables are similarly non-linear. 

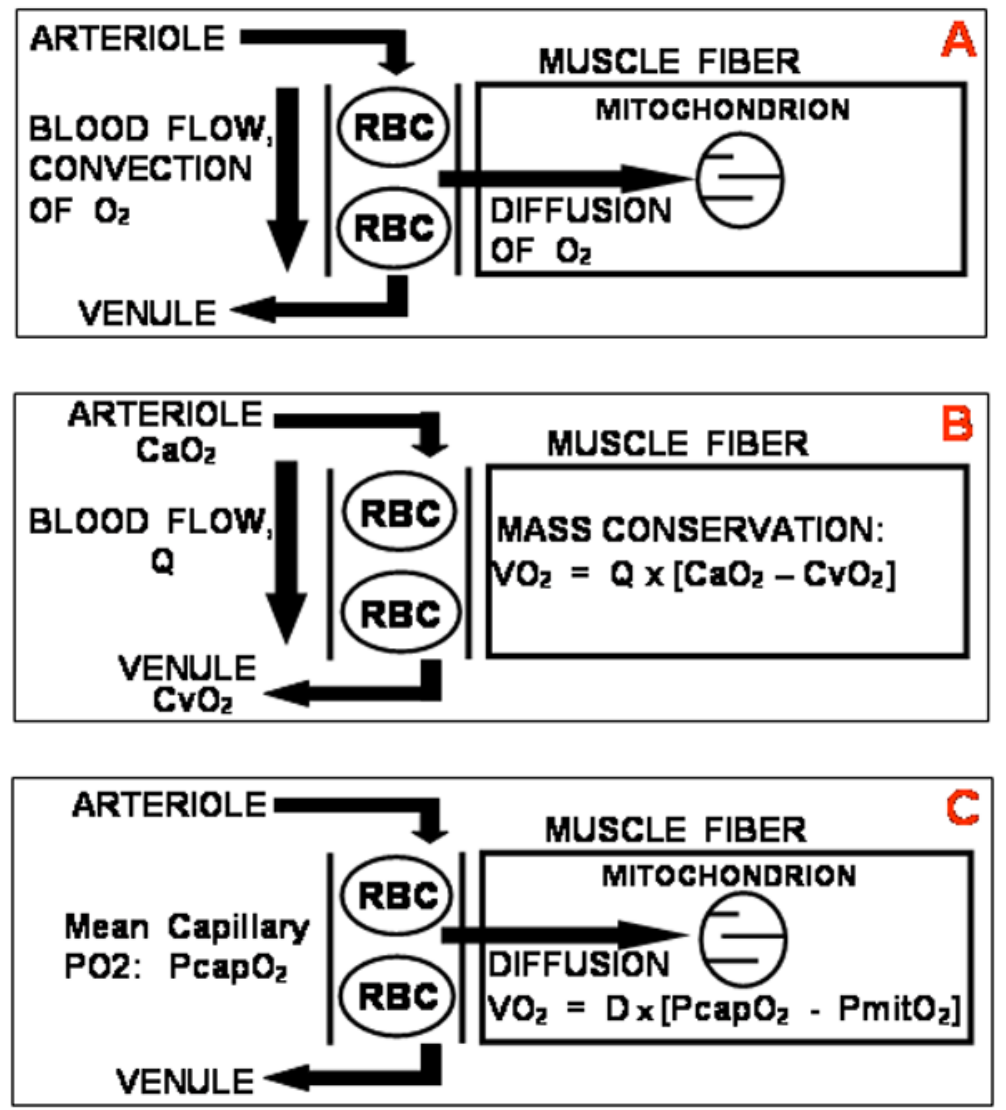

Figure 4.

Panel A: Concept of convective transport of $\mathrm{O}_{2}$ to the muscle by blood flow and simultaneous diffusive transport of $\mathrm{O}_{2}$ from red cells to mitochondria in muscle. Panel B: The convective transport component must obey the Fick principle of mass conservation. Panel C: The diffusive component must obey the laws of diffusion. 


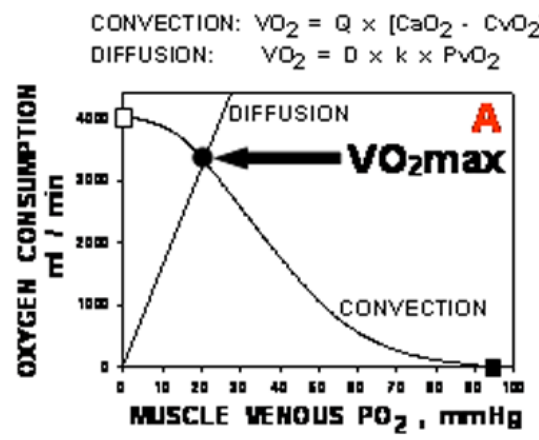

\section{REDUGE Diffusional Gonductance}

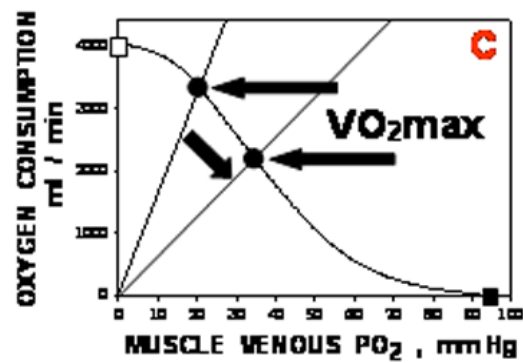

REDUGE $\mathrm{PaO}_{2}$ : HYPOXIA

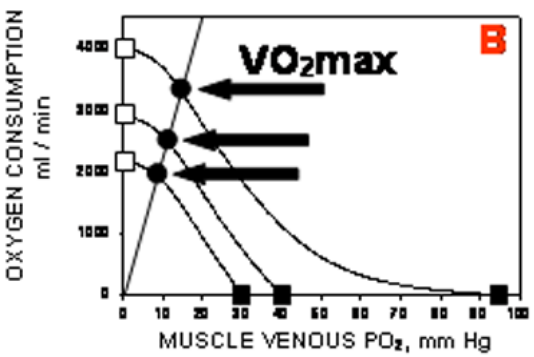

REDUGE BLOOD FLOW

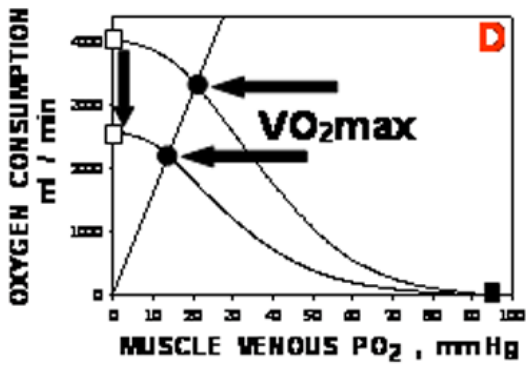

Figure 5.

Panel A: Bringing the circulatory convective and muscle diffusive components together on a diagram relating $\mathrm{VO}_{2}$ to $\mathrm{PvO}_{2}$. Panel B: Effects of progressive arterial hypoxemia on $\mathrm{VO}_{2} \mathrm{MAX}$; Panel C: Effects of reduced muscle diffusing capacity on $\mathrm{VO}_{2} \mathrm{MAX}$; Panel D: Effects of reduced muscle blood flow on $\mathrm{VO}_{2} \mathrm{MAX}$. See text for details. The key point is that each factor involved in $\mathrm{O}_{2}$ transport plays a role in setting $\mathrm{VO}_{2} \mathrm{MAX}$. 

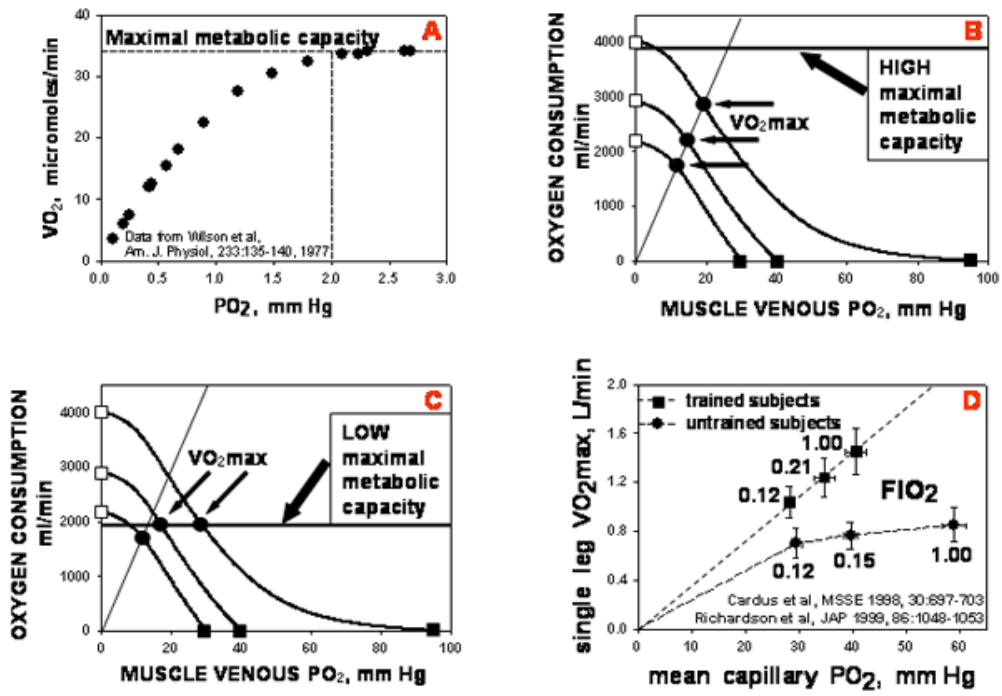

Figure 6.

Adding maximal mitochondrial oxidative capacity (MMOC) to the transport diagram of Figure 5. Panel A: MMOC is the highest, plateau value of $\mathrm{VO}_{2}$ when $\mathrm{PO}_{2}$ no longer affects $\mathrm{V}_{2}$ [13]. Panel B: When MMOC exceeds maximal $\mathrm{O}_{2}$ transport capacity, the latter determines $\mathrm{VO}_{2} \mathrm{MAX}$ just as in Figure 5. Panel $\mathrm{C}$ : When MMOC is less than maximal $\mathrm{O}_{2}$ transport capacity at any $\mathrm{FIO}_{2}, \mathrm{MMOC}$ and not transport limits $\mathrm{VO}_{2} \mathrm{MAX}$. Panel D:

Experimental data showing that fit subjects are limited by $\mathrm{O}_{2}$ transport while unfit subjects are essentially limited by MMOC (until $\mathrm{FIO}_{2}$ is reduced substantially). 